\title{
A new face for an old disease: some reflections on the role of the media in Nepal's first National Leprosy Elimination Campaign
}

\author{
PATRICK LYNCH \\ Nepal Leprosy Trust, PO Box 96, Kathmandu, Nepal \\ Accepted for publication 1 December 1999
}

\begin{abstract}
'This campaign has achieved more in four months than I have achieved in 45 years working in leprosy'

Eileen Lodge

\section{Introduction}

This article reports briefly on the Media Campaign run in conjunction with Nepal's first National Leprosy Elimination Campaign. The article is not intended to be a scientific evaluation of the Campaign's effectiveness but rather information about the Campaign itself and personal reflections from some of those involved and who were both impressed and challenged by its impact.
\end{abstract}

\section{Background}

In 1997 the World Health Organisation decided on a number of initiatives to accelerate the elimination of leprosy in endemic countries. One of these was to engage the BBC-MPM (Marshall Plan of the Mind) Trust (a Charitable Trust set up by the BBC) to investigate the possibility of organizing a large media-based leprosy awareness campaign in five endemic countries (Nepal, India, Brazil, Ethiopia and Indonesia). With financial support from the Novartis Foundation for Sustainable Development, BBC-MPM undertook a 5-month feasibility study. At the end of this time it was agreed that a major Media Campaign in leprosy was both feasible and desirable. Following the study, a proposal was prepared and work began on planning individual country campaigns to (in the words of BBC-MPM's Editor Mr Roy Head), give a 'new face to an old disease'.

Nepal was the first of the five countries to undertake the Campaign, as His Majesty's Government had already decided to undertake a National Leprosy Elimination Campaign (NLEC) in the autumn of 1998 (later re-scheduled to January 1999). The Media Campaign was enthusiastically embraced as a core component of the NLEC.

Eileen Lodge is the co-founder of Green Pastures Hospital and founder of the Nepal Leprosy Trust and the Nepal Leprosy Fellowship. 


\section{Campaign aims}

As soon as the project was approved, the Leprosy Control Division Director, Dr J. P. Baral, met with various partners and agreed the threefold aims of the Media Campaign to be:

1. To raise public awareness about the symptoms of leprosy.

2. To inform the community that leprosy is curable and that medicine is available free of charge.

3. To reduce the stigma and fear associated with leprosy.

\section{Campaign strategy}

While the aims of the Campaign were quite typical, the strategy adopted to communicate them was not, BBC-MPM developed a multi-faceted approach with many innovative components to ensure the effective communication of the three core messages. These key components included:

- Skilled co-ordination

BBC-MPM who had undertaken the original feasibility study were given the contract by WHO to co-ordinate the electronic media Campaign. In October 1998, BBC-MPM appointed as Co-ordinator to the project one of its experienced producers, Ms Susan Mackay who had just finished another media project in Mongolia. Her energy and enthusiasm were infectious and largely fuelled the momentum, excitement, and vision generated in the Campaign.

- In-country media

Early meetings were held with Nepal State television and radio, both of whom showed a high level of interest in and commitment to the Campaign. This meant that important airtime deals could be agreed fairly early in the planning process.

In fulfillment of one of the aims of BBC-MPM to build up local broadcasting capacity, and therefore the sustainability of the project, Ms Mackay set about searching for and recruiting some of the best local producers and media professionals. Following discussions with a number of government and NGO officials, it became evident that the Academy of Audio Visual Arts and Sciences (AA-VAS), based in Kathmandu, was the foremost local organization in creative media. AA-VAS is a non-profit centre dedicated to developing skills in the communication arts and sciences. This partnership led to one of the most important outcomes of the Campaign. The AA-VAS team led by Deependra Gauchan quickly became convinced by the Campaign's message and goals. Within a short time, AA-VAS agreed to undertake the whole Campaign and became one of its most committed proponents. AA-VAS invested large amounts of time and creative energy into getting 'inside' leprosy so that they could find effective ways of communicating this to others. Frequent late night editing sessions were evidence of the commitment of the team to their work. Extensive field tours were also undertaken, with much time spent meeting people affected by leprosy. The team wanted to 'touch' leprosy - and they did. As a result of this approach, people affected by leprosy were to become the real stars of the Media Campaign. 


\section{INVOLVEMENT OF PEOPLE AFFECTED BY LEPROSY}

One of the most impressive aspects of the Campaign was the involvement of people affected by leprosy. Throughout the planning process the AA-VAS team kept in touch with the heart of the Campaign through ongoing meetings and discussions with people affected by leprosy. Through this interaction, the idea was born to feature the experiences of some of these people as core components of the Campaign. Six people were invited to participate. All were charismatic personalities, who had had different experiences of the disease. They ranged from those who had no impairments to those who had been completely rejected by their families and communities. Some were senior professionals (bank manager, teacher, nurse) and others were semi-skilled workers. The one thing they all had in common was that they had overcome leprosy, not only physically but also socially, emotionally and psychologically. Short TV/radio spots that interviewed these people at home and at work were produced. These features did not seek to hide leprosy but rather were a powerful tool to demonstrate that the disease could truly be overcome and was therefore not to be feared.

A most effective poster collage of nine people some of whom had been featured in the TV/radio spots was produced, headed by the question, 'Which of these people has leprosy'? Below, the simple answer was given 'None, they have all been cured'. The poster which was colourful, attractive and showed nine happy and obviously fulfilled people, was in stark contrast to many of the images more usually used to educate about leprosy.

Two celebrities involved in the Campaign were also photographed interacting with people affected by leprosy. These images were used in another series of posters. The impact was very striking, particularly in a society where public figures would not normally be identified with a disease such as leprosy.

\section{BASELINE SURVEY AND FOCUS GROUPS}

Another important activity undertaken at the beginning of the Campaign planning phase was the commissioning of a baseline survey. One of the top market research companies in Nepal, New Era, was recruited and a questionnaire developed for use in carefully selected sample areas throughout the country. The baseline survey had three purposes:

- To provide the baseline position against which to compare any changes in knowledge and attitude resulting from the Campaign.

- That information on the current knowledge about and attitudes to leprosy would guide how the Campaign messages should be presented.

- To describe the availability of various forms of media in Nepal, to ensure appropriate use of different materials.

There were no particular surprises in the survey. When the baseline results were published, poor knowledge and attitude to leprosy were confirmed and the need for a Campaign of this sort was reinforced.

Furthermore, the survey also highlighted that approximately $51 \%$ of Nepali homes have access to radio and only $20 \%$ to $\mathrm{TV}$. This pointed to the need for other methods of communicating the Campaign messages at the local level.

New Era also conducted a series of independent focus group discussions in three districts to assess the suitability of IEC materials as they were produced. 
Following the publishing of the baseline survey, the project was ready to forge ahead with preparing a broad range of media materials. The government immediately set to work to produce its own package of posters and leaflets that would be used extensively throughout the country to promote the forthcoming NLEC. BBC-MPM and AA-VAS started on the production of its range of complementary media materials. These included:

- TV adverts - short adverts counting down to the campaign were broadcast twice nightly for the 10 days before the Campaign.

- A tele-film - a half-hour comedy written and produced by Nepal's two top film/TV personalities.

- TV spots - three spots featuring two well known celebrities and based on famous scenes from the Nepali films were produced with leprosy as the core message.

- Radio spots - there was a five-part discussion programme involving the Director of the Leprosy Control Division and also featuring people affected by leprosy who had all successfully overcome the disease. A number of short radio dramas about leprosy were also produced.

- TV/chat programmes - a number of general interest/current affairs programmes focussing on leprosy.

- Posters - three posters were produced portraying positive images of people affected by leprosy. Three further posters were produced by the government, giving information about the disease and the NLEC Campaign.

- School materials - an attractive colouring book telling the story of a boy affected by leprosy was produced for schools.

- POP/folk songs - four songs/jingles were written by well-known song-writers. A CD was produced and the songs were broadcast regularly on state radio and private FM stations. A theme song was also written for the Campaign.

- Commissioned written articles - the British Embassy supported an initiative through the Nepal Press Institute for five press fellowships, for journalists to write considered articles on the experiences of people affected by leprosy.

\section{INVOLVEMENT OF CELEBRITIES}

One of the principal tasks in the early planning of the electronic Media Campaign was to find key celebrities who would not only endorse the Campaign but would also play a leading role in the Campaign itself. Madan Krishna Shrestha and Hari Bamsha Acharya ('MaHa'), Nepal's top film and TV personalities and the two most widely known personalities in the country, agreed to do the advertisements (for free) and TV drama (at a much reduced cost). In a novel approach to the advertisements 'MaHa' took some of the most famous scenes from their highly popular films and re-enacted them with leprosy as the key message. Both the advertisements and the tele-film were hilariously funny, but effectively and eloquently conveyed the message that leprosy was curable and not to be feared. (A new 'MaHa' movie is greeted with the same sort of enthusiasm and excitement as a new Mr Bean movies would be in the UK!) 'MaHa' had some prior interest in leprosy and had been in discussions with a local NGO to develop a film that would raise awareness about leprosy. One of the ongoing benefits of the Campaign is the continued interest and commitment of people like 'MaHa' to the work of eliminating leprosy and its stigma. 


\section{CREATIVITY}

The Media Campaign was driven by people expert in creative media. Some of us 'leprosy experts' were a little nervous at first about taking our hands off what we considered to be our field and leaving it to people who knew little about leprosy. The result, however, was startling. The whole subject was seen with new eyes. Humour, colour and pop music were used to great effect alongside common symbols and themes. All of these features gave a new dynamic appearance to a subject that at best has been the object of fear.

\section{MOBILIZATION OF OTHER RESOURCES}

One of the other interesting outcomes of the Campaign was the amount of excitement and goodwill generated amongst a whole range of organizations (some not related to leprosy). International bodies, Embassies and NGOs were all willing to add funds, ideas and resources to the overall project. One initiative worth mentioning was a project to take the Campaign messages into areas with limited media access. One NGO recruited well-known Nepali actors and actresses to train 75 community group members from five endemic districts in Street Drama. These community groups using a communication form still very important in Nepal, conducted intensive, targeted campaigns in their own districts. The Street Drama programme proved to be a popular and effective means of communicating the message. A follow-up programme has already started with the support of the Sasakawa Memorial Health Foundation. Other health related programmes are now considering Street Drama initiatives as a means of health promotion.

\section{Campaign reflections}

The Campaign created tangible optimism amongst those associated with it. It was exciting, colourful and succeeded in touching the human side of leprosy. It certainly convinced many that the media was a resource grossly undervalued in the fight against leprosy.

The use of humour mentioned already was an interesting and successful medium in the Campaign. Comedy is an important form of communication in Nepal and the leprosy Campaign used it to great effect both in the electronic media component and in activities like the Street Drama Programme. While not reducing the seriousness of leprosy it gave light and humanity to a subject that for too long had been shrouded in fear and darkness.

The many positive images of people affected by leprosy but who had overcome the disease were also very refreshing.

The culmination of the whole Media Campaign was of course the NLEC Search Week. This was itself a success. Thousands of government health workers in 27 districts were mobilised and in the 6-day search period almost 12,000 new cases were identified. The message about NLEC seemed to have reached almost everywhere (there were phone calls to district health offices requesting a visit when teams did not reach them at the right time). The comment made again and again by government officials, NGO staff and others, was how easily people reported for treatment. It appeared that the usual fear of stigma, expected to hinder people from coming forward was generally not in evidence during the Search Week. This was surprising as changing of attitudes at this level is usually a much longer term affair. 


\section{Where to now?}

The Media Campaign in Nepal left many of us working in the field of leprosy feeling very encouraged. We were particularly delighted at how much had been achieved in such a short time when people with expertise, energy and creativity were given the opportunity to cross the boundaries of 'Our World'. Already in Nepal we are looking for ways to followup on this first programme, to ensure the momentum gained is not lost. We have had a glimpse of a powerful resource, not so far fully utilized. How can we make full use of it?

In the midst of this excitement we should offer one small word of caution. Media Campaigns can do a lot for leprosy. They can help effectively get the message across, can change attitudes and much, much more. We as leprosy agencies must ensure that the service we are asking media experts to 'advertise' is as good as the 'advertisement' promise. If not we run the risk of losing much public trust and goodwill, which once lost will be difficult to regain. The NLEC Media Campaign in Nepal cannot have been finally called a success until every person identified during the Campaign has been cured.

With the caution, perhaps I should add a challenge. Media campaigns are by nature expensive and tangible results are not always immediately obvious. With more and more funding organizations seeking short-term easily measurable results from their investments, there may be a danger that the benefits to be gained from a resource like the media will not be pursued. Are donor agencies ready to invest more resources in the process of education and changing attitudes?

The Nepal experience so far, however, is a very positive one and gives us confidence for the future. For many of us involved in leprosy work in Nepal, we are convinced it is an investment worth making. In the words of Ram Nandan Mahara, a person affected by leprosy who featured in the Campaign: "The villagers had several meetings and they tried to kick me out of the village. At that time I felt like committing suicide... now all the villagers call me 'Hakim' (leader). A leader! 'Oh, Ram Nandan is an important man-a leader.' If resources like the media can help us to turn lives around, then let us work with them as partners, to ensure we do it.

\section{Theme song for the campaign}

The theme song was designed to comfort the issue of social stigma. The lyrics of the ballad do not mention leprosy directly, rather imply that the singer was made a social outcast for a problem brought on him by his fate. The singer confronts the audience with his feelings, challenging them to identify with him, and to see him as a person just like them. The song builds to a climax where he has the courage to take charge of his own destiny. The song concludes with a voice-over carrying the campaign messages. 


\section{KUN JUNIKA PAAP HO}

Some say it's the result of sins in a former life

Some say it's a curse from a former life

But more than my wounds it hurts me more

When some say my life is over

Friends turned away, friends left my side

I don't mind the attitude of others

But even my very own cut off ties from me

I became a speck of dust in the eye

I became a thorn in the flesh

I'm a person too

Although I'm human I became distanced from humanity

What's the difference between you and me?

I'm just like you too

I, too have feelings

I'm a person just like you

I too have desires, let me weave my own sweet dreams

I'm a person, let me live like one

Sins, curses don't mean a thing

I'll write my own destiny

I'm a person, I'll put together my world

\section{VOICE OVER}

It's not a sin, it's not a curse

Leprosy is just a simple disease

If you recognize the signs and get treatment on time, you can be cured

Let's get treatment on time

Let's chase the disease, not the people out of our community

Let's make a leprosy free society

Let's increase mutual understanding 


\section{Examples of stories used for the radio dramas}

MAN KO BAGH (THE DEMON WITHIN)

The drama has a rural setting and deals with the relationship between husband and wife when he discovers that she is taking medicine secretly. He fears that she is taking contraceptives without his consent and rather than confronting her he visits the health post to seek the doctor's advice. He learns that she has leprosy and as she is on treatment he and his daughter are not at risk.

However, he still has many doubts and finds the courage to share the secret with a friend. $\mathrm{He}$ is shocked to find that his friend already knew. Additionally, he discovers that this friend also had leprosy but is now cured. As the friend and his wife have just given birth to a child this helps to convince him that it is safe to be close to his wife.

\section{THE WEDDING}

The problem of arranging marriages in a family affected by leprosy is one of the most challenging social issues of leprosy. This drama tells the story of a professor, a former leprosy sufferer, trying to arrange the match of his daughter. Two previous matches have failed once the families learnt of his disease.

A prospective groom is found for the girl and negotiations take place. The family is a little surprised to see that the father of the groom is not present at the negotiations and although they like the boy, and he and his aunt seem keen, they are not sure that it can go ahead. Despite the protestations of the matchmaker, they are determined to be very open with their prospective in-laws and the professor tells them about his disease and that he has been cured.

The girl's family are not the slightest bit discouraged. The matchmaker is keen to know what they think of the boy. Once he is reassured that they like him he reveals himself as the boy's father. He explains that he entered the subterfuge because he wanted to be sure that they liked the boy for his own merits. He makes it clear that he is not worried at all by the fact that the professor had leprosy. He was more worried that their family would not want her to marry the son of a matchmaker.

\section{Quotations from people involved in the campaign}

This, (the campaign) in my opinion, marks a chapter in Nepal's history of changing people's attitudes towards not just leprosy but towards every other disease or social problem where the affected persons feel stigmatized. The brave people who spoke out when given the opportunity will work as pathbreakers for other persons afflicted by other taboo diseases or difference of opinion. The key elements that came through were HOPE, DETERMINATION AND COURAGE. 
Yashodha Jiriel cried when she heard the NLEC theme song because she felt it expressed to all how a person affected by leprosy feels deep within. Being able to break through and share this pain with everyone gave her a sense of liberation she had never felt before. It lifted a huge burden. She said, 'Leprosy used to be a disease I hated. But today, I feel I'm lucky to have had the disease. It guided me on the path I was meant to take, helping people in pain'.

Yashoda Jiriel (Nurse)

'My daughter is studying in school. I work hard to educate her so that she will grow up and become a nurse or a teacher and she will teach people not to shun people affected by leprosy. She will teach people that we are all the same-leprosy affected or not' 